\title{
OBTENÇÃO DE INSUMOS PETROQUÍMICOS POR HIDROCRQUEAMENTO DE ÓLEO DE SOJA BRUTO COM CATALISADOR COMERCIAL DE FCC
}

\author{
C. H. ZANDONAI ${ }^{1 *}$, P. H. YASSUE-CORDEIRO ${ }^{2}$, A. P. SONE ${ }^{2}$, S. B. C. \\ PERGHER $^{3}$, M. L. GIMENES ${ }^{2}$, N. R. C. FERNANDES-MACHADO ${ }^{2}$ \\ ${ }^{1}$ Universidade Estadual de Maringá - Departamento de Tecnologia \\ ${ }^{2}$ Universidade Estadual de Maringá - Departamento de Engenharia Química \\ ${ }^{3}$ Universidade Federal do Rio Grande do Norte, Departamento de Química \\ E-mail para contato: chzandonai@gmail.com
}

\begin{abstract}
RESUMO - A utilização de matéria prima fóssil vem gerando diversos impactos ambientais. Como alternativa é possível se obter esses insumos através do craqueamento catalítico de óleos vegetais. Nesse trabalho foi utilizado óleo de soja bruto e o catalisador comercial de FCC, no processo de hidrocraqueamento em um reator de leito fixo a $450^{\circ} \mathrm{C}$, durante duas horas. Os produtos foram analisador por cromatografia a gás acoplada a espectro de massas. A caracterização do material foi realizada por ressonância magnética nuclear de ${ }^{29} \mathrm{Si}$ $\mathrm{e}^{27} \mathrm{Al}$, dessorção e dessorção de nitrogênio e dessorção à temperatura programada de amônia. $\mathrm{O}$ coque foi quantificado por oxidação à temperatura programada. $\mathrm{O}$ catalisador se mostrou eficiente no processo de desoxigenação por descarboxilação, obtendo boa seletividade a hidrocarbonetos. O tempo de exposição do catalisador às condições reacionais modificou a seletividade e o perfil de produtos, principalmente pela deposição de coque.
\end{abstract}

\section{INTRODUÇÃO}

A exploração de energia de origem fóssil, principalmente empregado como combustível vem causando impactos ambientais e gerando custos indiretos devido à poluição (BARBIR et al., 1990). A fim de se evitar essa situação, tem-se objetivo de substituir essa fonte de energia esgotável por uma renovável. A produção dos hidrocarbonetos líquidos e gasosos pelo processo de craqueamento, tendo como matéria prima óleo vegetal, apresenta uma alternativa para este fim. Esse processo gera hidrocarbonetos de diversas classes de compostos, tendo diferentes empregos na indústria petroquímica, livres de enxofre, nitrogênio e metais pesados (TIAN et al., 2008).

Este trabalho teve por objetivo explorar a aplicação do catalisador comercial de FCC, empregado no craqueamento de petróleo, na tecnologia de craqueamento catalítico de óleo vegetal de forma experimental a fim de avaliar o desempenho do catalisador. Para isso foram realizados testes em laboratório, onde foi avaliado a alteração no perfil de produtos do processo ao longo do tempo de reação. 


\subsection{Craqueamento de Óleo Vegetal}

O craqueamento de óleos vegetais tem por objetivo produzir hidrocarbonetos a partir dessa matéria prima, pela decomposição termocatalítica das moléculas de triglicerídeos do óleo, além da desoxigenação das mesmas. Como o descrito por Dupain et al. (2007) a fragmentação do triglicerídeo ocorre por efeitos térmicos e pela interação com os sítios ácidos, onde as ligações entre os oxigênios do ácido graxo e os carbonos do glicerídeo são quebradas, gerando ácidos graxos livres e uma molécula de propano insaturada.

De acordo com Yang et al. (2013) há dois principais meios para que ocorra a desoxigenação dos ácidos orgânicos. Quando ocorre a cisão- $\alpha$ da ligação carbono-carbono da carboxila gerando uma molécula de dióxido de carbono, dá-se a descarboxilação, gerando um hidrocarboneto com um número de átomos carbono menor que à do ácido original. Quando o meio é rico em hidrogênio, onde os oxigênios da carboxila do ácido são atacados por esse, gerando duas moléculas de água e um hidrocarboneto com cadeia carbônica de mesmo tamanho que a do ácido original, dá-se então a hidrodesoxigenação.

Diversos óleos vegetais já foram avaliados no processo de craqueamento catalítico, óleo de canola (KATIKANENI et al., 1995), de girassol (DANDIK; AKSOY, 1998), de palma (TWAIQ et al., 2004), e os experimentos mostram que há uma baixa sensibilidade do processo quanto à matéria, onde os produtos obtidos apresentam elevada quantidade de hidrocarbonetos.

O principal constituinte do catalisador comercial de fcc é a zeólita Y, além de aglomerante, matriz e carga. Doronin et al. (2012) realizaram craqueamento catalítico de óleo de girassol com HY e HZSM-5. O reator utilizado apresentava a configuração de leito fixo. Sua operação foi realizada a $450{ }^{\circ} \mathrm{C}$ sob fluxo de gás nitrogênio e a velocidade espacial de $30 \mathrm{~h}^{-1}$. O catalisador utilizado foi HY, variando-se a concentração de HZSM-5 em sua composição para avaliar o seu efeito na distribuição dos produtos. O catalisador HY foi mais seletivo a hidrocarbonetos na faixa da gasolina. Com o acréscimo de HZSM-5 na composição do compósito HY-HZSM-5, fragmentou-se mais as moléculas, gerando mais hidrocarbonetos gasosos que líquidos.

\section{MATERIAIS E MÉTODOS}

\subsection{Testes Experimentais de Craqueamento}

Foi utilizado óleo de soja não sujeito a degomagem ou clarificação, obtido junto à linha de produção, dito bruto, cujos triglicerídeos são compostos pelos ácidos palmítico (13\%), oleico $(38 \%)$ e linoleico (49\%). Para a avaliação do catalisador foram realizados testes experimentais foram em reator tubular de leito fixo, com 4 góleo/h.gcat. Foi realizada a ativação prévia do catalisador, sob fluxo de $40 \mathrm{~mL} / \mathrm{min}$ de nitrogênio durante uma hora a $500^{\circ} \mathrm{C}$, no reator. A reação foi conduzida a $450^{\circ} \mathrm{C}$ sob fluxo de $40 \mathrm{~mL} / \mathrm{min}$ de hidrogênio, com $1 \mathrm{~g}$ de catalisador, com diâmetro médio de partícula de $589 \mu \mathrm{m}$, durante $2 \mathrm{~h}$. Para a alimentação do óleo de soja foi utilizada bomba tipo cilindro-pistão. A separação dos produtos gasosos dos líquidos se deu em um condensador, à temperatura de fusão do gelo. $\mathrm{O}$ produto líquido apresentou duas fases, aquosa e orgânica, onde a separação foi realizada via centrifugação a 1025 G. O produto gasoso foi coletado com seringa na saída do condensador via septo. 


\subsection{Análise dos Produtos do Craqueamento}

Através da cromatografia gasosa, detectou-se a composição do produto gasoso, utilizouse um cromatógrafo com detector de condutividade térmica (TCD), equipado com uma coluna Porapak Q (3,15 mm de diâmetro e $90 \mathrm{~cm}$ de comprimento). Os picos foram identificados pela injeção de misturas gasosas padrões de $\mathrm{CO}, \mathrm{CO} 2, \mathrm{CH} 4$, Etano, Eteno, Propano, Propeno, Butano, N2 e H2O. A análise ocorreu sob a programação: $130^{\circ} \mathrm{C}$ de temperatura inicial, mantida por $4 \mathrm{~min}$, seguida de uma rampa de $20^{\circ} \mathrm{C} / \mathrm{min}$ até $160^{\circ} \mathrm{C}$ mantida por $7 \mathrm{~min}$.

Através de cromatográfica gasosa acoplada a espectro de massas (CG-MS) se determinou a composição do produto, em equipamento CG-MS Thermo-Finigan, com cromatógrafo em fase gasosa FOCUS GC (Thermo Electron), acoplado a um espectrômetro de massas DSQ II (Thermo Electron), com coluna DB-5, com $30 \mathrm{~m}$ de comprimento. A análise ocorreu sob a programação: um patamar inicial $50^{\circ} \mathrm{C}$, mantido por um minuto; rampa de $4^{\circ} \mathrm{C} / \mathrm{min}$ até $250^{\circ} \mathrm{C}$, mantida por $10 \mathrm{~min}$, semelhante a Chen et. al. (2010). Os componentes foram identificados de acordo com a massa de seus íons na biblioteca do equipamento.

A presença de ácidos graxos, incompatíveis com a fase da coluna cromatográfica que separa hidrocarbonetos, fez necessária a realização de um pré-tratamento da amostra. Fez-se então uma metilação por catálise ácida, adaptada de Hartman e Lago (1973). Adicionou-se em um tubo de ensaio $100 \mathrm{mg}$ do produto líquido, em seguida adicionou-se $2 \mathrm{~mL}$ da solução hidróxido de sódio a $0,5 \mathrm{~mol} / 1$. Aqueceu-se o tubo em banho termostático a $90^{\circ} \mathrm{C}$ por $5 \mathrm{~min} \mathrm{e}$ após um rápido resfriamento em água corrente, adicionou-se $3 \mathrm{~mL}$ do agente de esterificação (33,33 g de cloreto de amônio e $50 \mathrm{~mL}$ de ácido sulfúrico em um litro de metanol). Realizouse mais um aquecimento da amostra até $90^{\circ} \mathrm{C}$ por $3 \mathrm{~min}$, após o resfriamento se adicionou 2 $\mathrm{mL}$ de solução saturada de cloreto de sódio, para separar as fases. Por fim se adicionou $3 \mathrm{~mL}$ de solvente não presente na amostra, neste caso iso-pentano.

Para quantificação do coque formado no catalisador se realizou testes de oxidação à temperatura programada (OTP), em um equipamento CHEMBET 3000 da Quantachrome, acoplado a um espectrômetro de massas THERMOSTAR ${ }^{\mathrm{TM}}$ da Pfeiffer Vacuum, utilizandose um reator de quartzo. De modo a se quantificar o reagente $\mathrm{O}_{2}$ e os produtos $\mathrm{CO}_{2}$ e $\mathrm{CO}$, a área da curva foi relacionada com a área de volumes conhecidos injetados destes compostos, de acordo com a metodologia encontrada na literatura (LEOCADIO et al., 2004).

\subsection{Caracterização dos Catalisadores}

Para avaliar as características texturais do catalisador, utilizou-se adsorção de nitrogênio, em equipamento NOVA1000, QUANTACHROME. Para avaliar a fase cristalina do catalisador, realizou-se análise de difração de raios $\mathrm{X}$ em um equipamento difratômetro modelo D8 Advance, Bruker, com uma fonte de cobre, radiação $\mathrm{CuK} \alpha$, com varredura de $0,24^{\circ} / \mathrm{min}, 40 \mathrm{kV}$ e $50 \mathrm{~mA}$, a varredura $2 \theta$ foi variada de $5^{\circ}$ a $85^{\circ}$.

Para a análise dos sítios ácidos presentes no catalisador, realizou-se testes de dessorção à temperatura programada (DTP) em equipamento ChemBet 3000 da Quantachrome. Realizou-se a degaseificação da a mostra anteriormente à saturação de amônia. A saturação por amônia se deu a $100^{\circ} \mathrm{C}$ durante $1 \mathrm{~h}$, com mistura gasosa de $5 \%$ de amônia em nitrogênio. Em seguida se realizou a purga para a remoção a amônia fisissorvida. Para a dessorção foi realizada uma rampa de aquecimento de $10^{\circ} \mathrm{C} / \mathrm{min}$ até $700^{\circ} \mathrm{C}$ permanecendo nesta temperatura por mais 30 min. A quantificação foi feita através da integração da área da curva do equipamento. 
A determinação da razão entre as quantidades de átomos de silício e de alumínio (Si/Al), foi realizada a análise por ressonância magnética nuclear RMN, esta em equipamento Mercury Plus 300, da Varian, equipado com a sonda para a análise em sólidos CP/MAS $7 \mathrm{~mm}$ A operação ocorreu a 59,61 MHz para o núcleo 29Si.

\section{RESULTADOS E DISCUSSÕES}

\subsection{Caracterização dos Catalisadores}

A análise de difração de raios-X (Figura 1) mostrou que o catalisador de FCC apresenta a zeólita $\mathrm{Y}$ em sua composição, por apresentar picos de cristalinidade característicos de sua estrutura, conforme o mostrado por Treacy e Higgins (2001). Através do difratograma do caulim, apresentado por Worasith et al. (2011), é possível perceber que o pico encontrado em $2 \theta$ entre 20 e 22 é característico desse material, indicando o seu uso como carga.

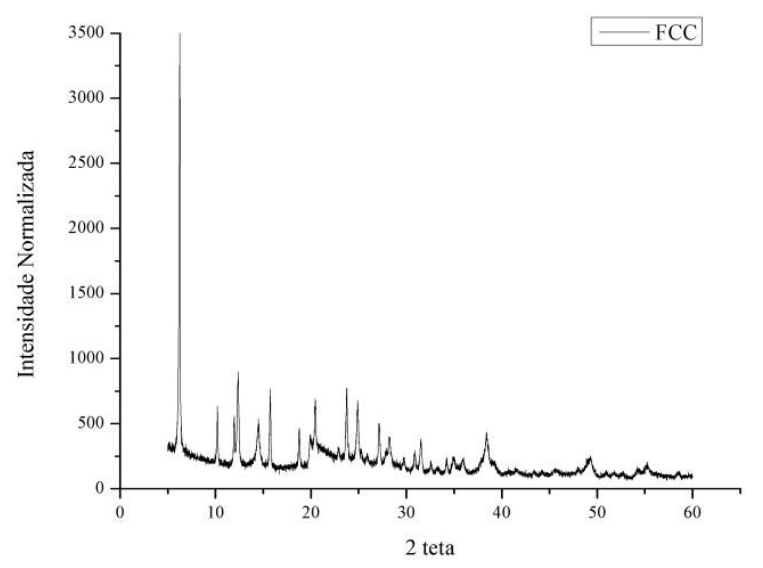

Figura 1 - Difratograma de raios-X do catalisador de FCC.

A análise de ressonância magnética de ${ }^{29} \mathrm{Si}$ apresentou todas as coordenações para os átomos de silício com os de alumínio, com nenhum, com um, dois, três e com quatro átomos de alumínio como é possível de se observar na figura 2 . A análise com ${ }^{27} \mathrm{Al}$ revelou picos de átomos de alumínio tetraédrico $(58,94 \mathrm{ppm})$ e octaédricos $(3,98 \mathrm{ppm})$ fora da rede cristalina da zeólita que compõem o catalisador. Os átomos de alumínios octaédricos, são dos outros componentes que fazem parte da estrutura do catalisador de FCC, como o caulim ou alumina. Através da integração dos picos do espectro de ressonância de ${ }^{29} \mathrm{Si}$, obtendo-se a área, encontrou-se a razão silício/alumínio estrutural de 1,66.
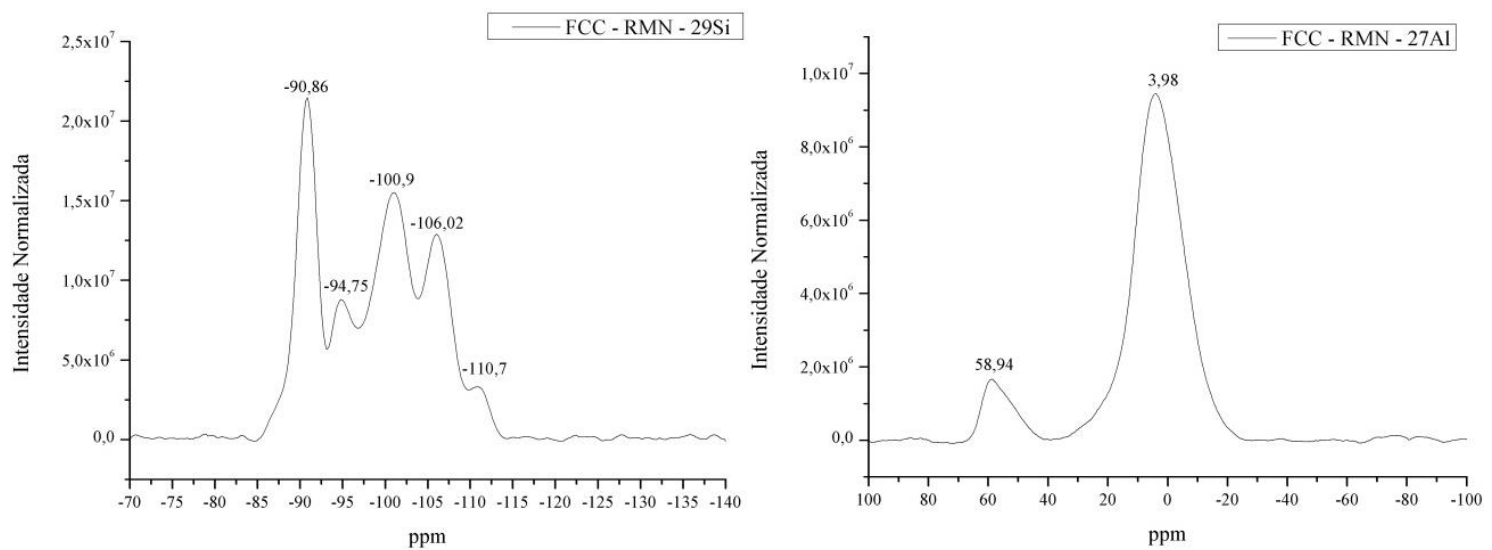

Figura 2 - Espectro de ressonância magnética nuclear ${ }^{29} \mathrm{Si} \mathrm{e}{ }^{27} \mathrm{Al}-\mathrm{FCC}$ 
A dessorção à temperatura programada mostrou que esse catalisador apresenta acidez, Figura 3. As diferentes temperaturas dos picos indicam que a amônia se adsorveu com diferente intensidade em diferentes sítios ácidos. A deconvolução dos picos mostrou a presença de 6 possíveis tipos de sítios, sendo estes dois sítios de acidez fraca $(232,97$ e $\left.270,26^{\circ} \mathrm{C}\right)$, dois de moderada $\left(354,89\right.$ e $\left.435,59^{\circ} \mathrm{C}\right)$ e dois de forte $\left(619,14\right.$ e $\left.579,21^{\circ} \mathrm{C}\right)$. Tal variedade de sítios é proveniente dos diversos materiais que compõe esse catalisador, como a matriz que pode ser ativa.

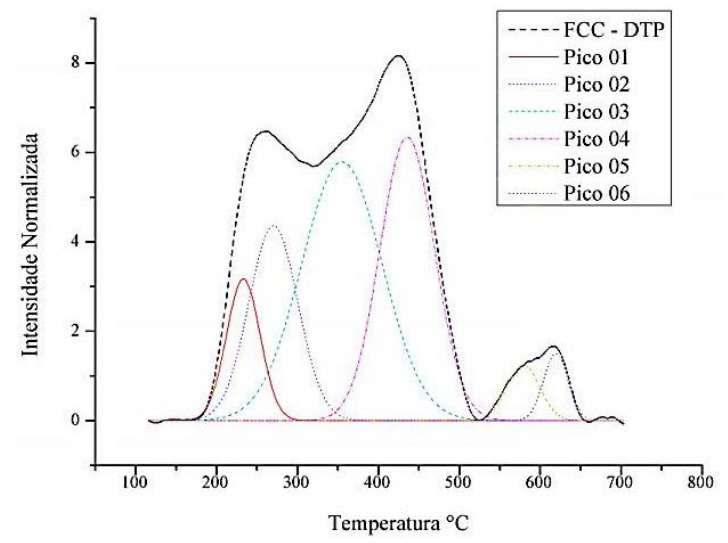

Figura 3 Dessorção à temperatura programada do catalisador de FCC

A Tabela 1 mostra os valores de acidez do catalisador, estes obtidos pela integração das curvas da Figura 4. A acidez total do material se mostrou baixa, de 48,10 mol de NH4/gcat. Isso principalmente devido à carga que compõe esse catalisador, que serve para reduzir a sua atividade.

Tabela 1 - Valores de Acidez para USY, NaY e HY

\begin{tabular}{|c|c|c|c|c|c|c|c|c|}
\hline \multicolumn{2}{|c|}{} & Pico 1 & Pico 2 & Pico 3 & Pico 4 & Pico 5 & Pico 6 & \\
\hline Temperatura & {$\left[{ }^{\circ} \mathrm{C}\right]$} & 232,97 & 270,26 & 354,89 & 435,59 & 619,14 & 579,21 & Total \\
\hline Acidez & $\frac{\text { mol de NH4 }}{\text { gcat }}$ & 4,24 & 8,52 & 18,52 & 13,76 & 1,46 & 1,62 & 48,1 \\
\hline
\end{tabular}

A análise de fisissorção de nitrogênio e a interpretação com a metodologia de BET e do método $t$ mostraram a porosidade do material. Na Tabela 2 é possível observar os valores de superfície específica, área de microporos e área externa.

Tabela 2 - Análise textural do catalisador de FCC

\begin{tabular}{|c|c|c|c|}
\hline $\begin{array}{c}\text { Superfície específica } \\
(\mathrm{BET})\left(\mathrm{m}^{2} / \mathrm{g}\right)\end{array}$ & \multicolumn{2}{|c|}{$\begin{array}{c}\text { Área de Microporos } \\
\left(\mathrm{m}^{2} / \mathrm{g}\right)\end{array}$} & $\begin{array}{c}\text { Área Externa } \\
\left(\mathrm{m}^{2} / \mathrm{g}\right)\end{array}$ \\
\hline 180 & \multicolumn{2}{|c|}{159,51} & 20,37 \\
\hline $\begin{array}{c}\text { Volume total } \\
\text { de poros } \\
\left(\mathrm{cm}^{3} / \mathrm{g}\right)^{*}\end{array}$ & $\begin{array}{c}\text { Diâmetro médio } \\
\text { do poro } \\
(\AA)\end{array}$ & $\begin{array}{c}\text { Volume de } \\
\text { microporos } \\
\left(\mathrm{cm}^{3} / \mathrm{g}\right)\end{array}$ & $\begin{array}{c}\text { Volume de } \\
\text { mesoporos } \\
\left(\mathrm{cm}^{3} / \mathrm{g}\right)\end{array}$ \\
\hline 0,11 & 24,26 & 0,088 & 0,010 \\
\hline
\end{tabular}

A superfície especifica encontrada é menor que a típica de zeólitas Y, isso por que materiais com baixa porosidade compõem o catalisador de FCC, diminuindo a porosidade final do material. Observa-se uma área de microporos maior que a de mesoporos, esta que é 
formada principalmente pela aglomeração de cristais. A zeólita Y que faz parte do material é microporosa.

\subsection{Produtos do Craqueamento}

O resultado dos testes de craqueamento será discutido através da exposição da concentração das espécies, agrupando-as pela quantidade de átomos de carbono dos hidrocarbonetos e dos grupos oxigenados. São discutidas também as quantidades de dióxido de carbono e de água, assim como a seletividade, esta representando a razão entre a quantidade de hidrocarbonetos (Hi) e a quantidade de oxigenados (Ox) produzidos.

Os hidrocarbonetos com de 1 a 4 átomos de carbono compõem a fração gasosa, os de 5 a 8 átomos carbono são os hidrocarbonetos leves, os de 9 a 18 átomos de carbono são os hidrocarbonetos pesados. Os grupos oxigenados são os ácidos que compõem os triglicerídeos do óleo de soja, os ácidos fragmentados são os com cadeia carbônica menor que os do óleo e que não estavam presentes no óleo. $\mathrm{O}$ grupo $\mathrm{R}-\mathrm{O}$ representa radicais oxigenados, tendo origem da hidrodesoxigenação parcial dos ácidos.

Na tabela 3, em 30 min de ração, a seletividade a hidrocarbonetos foi elevada, sendo esses principalmente gasosos, com quantidade moderada de pesados e leves. Isso indica que a essa temperatura a capacidade de fragmentação das moléculas orgânicas e da desoxigenação das mesmas é elevada. Esse processo que foi preferencialmente pela descarboxilação, como o indicado pela quantidade de dióxido de carbono produzido.

Após uma 1h de reação seletividade a hidrocarbonetos diminui, o que pode indicar a desativação dos sítios ácidos. Observa-se um grande aumento na quantidade de ácidos do óleo encontrados no produto, assim como a quantidade de ácidos fragmentados. A redução nas quantidades de dióxido de carbono e de água indica diminuição na desoxigenação das moléculas, estas ainda ocorrendo preferencialmente por descarboxilação.

Com 1:30 h de reação a seletividade a hidrocarbonetos cai abaixo da unidade, pelo aumento da concentração de oxigenados no produto. Observa-se que a quantidade de ácidos fragmentados acompanha a de ácidos do óleo, indicando a fragmentação destes sem a sua desoxigenação.

Tabela 3 - Distribuição de produtos do craqueamento.

\begin{tabular}{|c|c|c|c|c|c|c|c|c|c|}
\hline $\begin{array}{l}\text { Tempo } \\
\text { h:min }\end{array}$ & $\begin{array}{c}\text { C1- } \\
\text { C4 } \\
{[\%]}\end{array}$ & $\begin{array}{c}\text { C5- } \\
\text { C8 } \\
{[\%]}\end{array}$ & $\begin{array}{l}\text { C9- } \\
\text { C18 } \\
{[\%]}\end{array}$ & $\begin{array}{l}\text { Ac. } \\
\text { Óleo } \\
{[\%]}\end{array}$ & $\begin{array}{c}\text { Ac. } \\
\text { Frag. } \\
{[\%]}\end{array}$ & $\begin{array}{l}\text { R-O } \\
{[\%]}\end{array}$ & $\begin{array}{l}\mathrm{CO}_{2} \\
{[\%]}\end{array}$ & $\begin{array}{r}\mathrm{H}_{2} \mathrm{O} \\
{[\%]}\end{array}$ & $\mathrm{Hi} / \mathbf{O x}$ \\
\hline 00:30 & 31,89 & 16,86 & 19,49 & 1,3 & 1,58 & 0 & 19,62 & 9,26 & 23,67 \\
\hline 01:00 & 16,8 & 14,68 & 16,48 & 16,95 & 15,06 & 0 & 12,68 & 7,35 & 1,5 \\
\hline 01:30 & 13,03 & 10,55 & 5,81 & 39,67 & 16,68 & 0 & 8,66 & 5,6 & 0,52 \\
\hline 02:00 & 4,75 & 10,54 & 3,86 & 45,08 & 25,73 & 0 & 5,22 & 4,82 & 0,27 \\
\hline
\end{tabular}

Após 2:00 h diminuição na quantidade de desoxigenação reduz a seletividade à hidrocarbonetos. A pesar a redução a quantidade de hidrocarbonetos líquidos leves não diminui drasticamente. Isso pode indicar que mesmo após a inibição dos sítios, os ácidos continuam fragmentando-se sem que ocorra a desoxigenação.

Com o aumento da quantidade de ácidos do óleo no produto final, pode-se observar um aumento no numero de ácidos fragmentados. Na figura 5, agrupados como oxigenados, os 
esses ácidos são representados por $\mathrm{C}_{6} \mathrm{O}$ até $\mathrm{C}_{11} \mathrm{O}$, onde os que estão sempre em maior quantidade são $\mathrm{C}_{7} \mathrm{O}$ e $\mathrm{C}_{10} \mathrm{O}$, que correspondem à fragmentação da cadeia entre os carbonos 7 e 8 , e entre 10 e 11 , gerando hidrocarbonetos com 11 e 8 átomos de carbono.

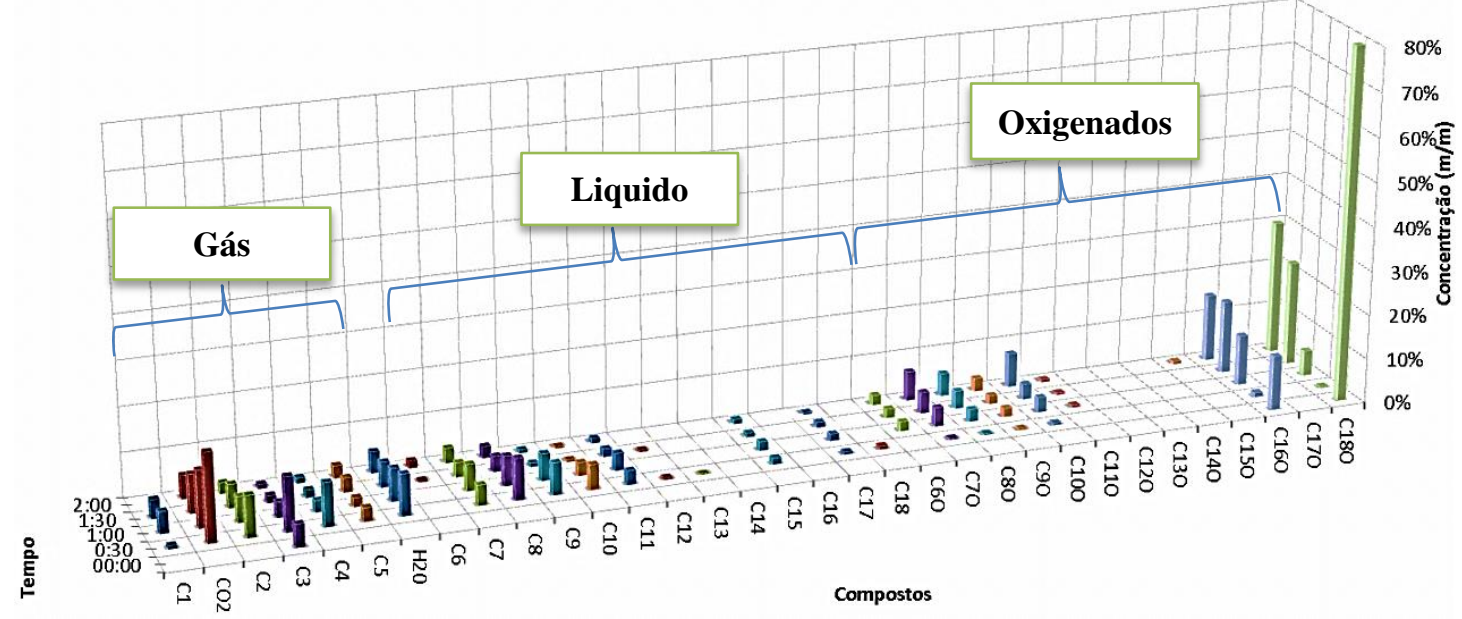

Figura 5 - Distribuição dos produtos por número de átomos de carbono

Dos hidrocarbonetos obtidos diretamente por hidrodesoxigenação ou descarboxilação é possível observar na Figura 5 os com 15 e 17 átomos, ao longo das $2 \mathrm{~h}$ de reação, provenientes da reação de descarboxilação, além dos com 18 átomos de carbono nos primeiros 30 min de reação, provenientes da reação de hidrodesoxigenação. Essa preferência pela descarboxilação também fica evidente na quantidade de dióxido de carbono produzido em relação à quantidade de água no produto final.

Juntando-se as diferentes classes de moléculas no produto líquido, independente do número de átomos de carbono, montou-se a Tabela 5. Ao longo do tempo se observa a redução na quantidade de aromáticos e o aumento na quantidade de alifáticos, pela inibição dos sítios que desidrogenam os hidrocarbonetos. Há também o aumento dos ácidos no produto pela inibição do processo de desoxigenação.

Tabela 5 - distribuição das classes de moléculas no produto líquido

\begin{tabular}{|c|c|c|c|c|c|}
\hline Tempo & Aromáticos & Cíclicos & Alifáticos & Ácidos & R-O \\
\hline $00: 30$ & $27,35 \%$ & $0,68 \%$ & $5,28 \%$ & $2,88 \%$ & $0,00 \%$ \\
\hline $01: 00$ & $9,95 \%$ & $1,38 \%$ & $17,78 \%$ & $32,01 \%$ & $0,00 \%$ \\
\hline $01: 30$ & $2,51 \%$ & $0,00 \%$ & $10,55 \%$ & $55,28 \%$ & $1,06 \%$ \\
\hline $02: 00$ & $0,92 \%$ & $2,11 \%$ & $8,53 \%$ & $69,18 \%$ & $1,63 \%$ \\
\hline
\end{tabular}

Através da OTP, Figura 6, observa-se o pico de oxidação do coque depositado sobre o catalisador, após $2 \mathrm{~h}$ de reação, em torno de $640{ }^{\circ} \mathrm{C}$. A integração do pico revelou uma

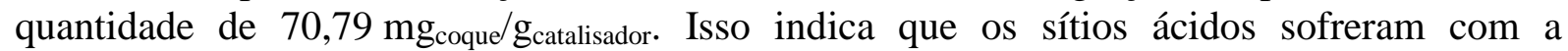
deposição de coque modificando a sua atividade ao longo do tempo de reação. O perfil de produtos foi alterado ao longo do tempo de exposição do catalisador ao meio reacional. Isso indica que através da alteração desse tempo de exposição é possível a obtenção de diferentes moléculas orgânicas, pela atividade inibida com a deposição de coque. 


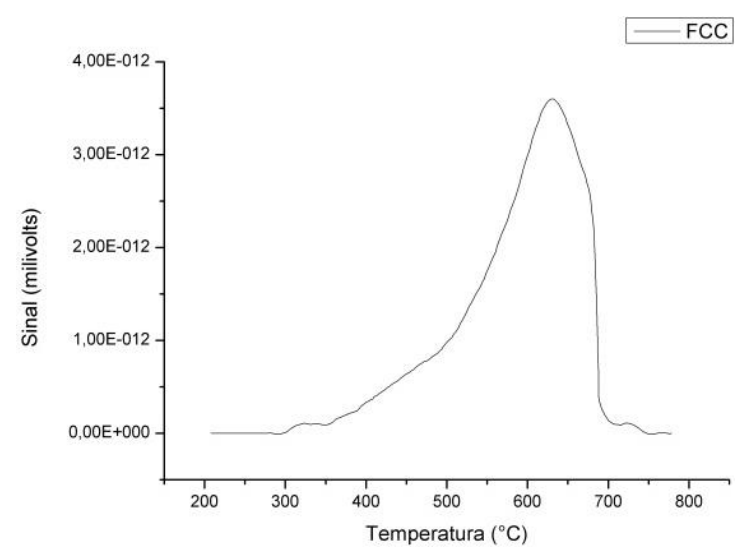

Figura 6 - Oxidação à temperatura programada (OPT)

\section{CONCLUSÃO}

Através do hidrocraqueamento de óleo de soja, obteve-se uma variedade de moléculas orgânicas que são insumos da indústria petrolífera. A exposição do catalisador ao meio reacional modificou sua atividade, obtendo-se diferentes moléculas para diferentes tempos de exposição, o que pode ser explorado em processamentos em leitos com recirculação contínua.

\section{REFERÊNCIAS}

BARBIR, F.; VEZIROĞLU, T.; HJ PLASS, J. Environmental damage due to fossil fuels use. Intern. J. of Hydrogen Energy, v. 15, n. 10, p. 739-749, 1990.

CHEN, Y.; WANG, C.; LU, W.; YANG, Z. Study of the co-deoxy-liquefaction of biomass and vegetable oil for hydrocarbon oil production. Bioresource technology, v. 101, n. 12, p. 4600-7, 2010. Elsevier Ltd.

DUPAIN, X.; COSTA, D. J.; SCHAVERIEN, C. J.; MAKKEE, M.; MOULIJN, J. Cracking of a rapeseed vegetable oil under realistic FCC conditions. App. Cat. B: Env., v. 72, n. 1-2, p. 44-61, 2007.

HARTMAN, L.; LAGO, R. C. A. Rapid preparation of fatty acid methyl from lipids. Laboratory Practice, v. 22, n. 3, p. 475-473, 1973.

MELERO, J. A.; ClAVERO, M. M.; CALlEJA, G.; et al. Production of Biofuels via the Catalytic Cracking of Mixtures of Crude Vegetable Oils and Nonedible Animal Fats with Vacuum Gas Oil. Energy \& Fuels, v. 24, n. 1, p. 707-717, 2010.

TIAN, H.; LI, C.; YANG, C.; SHAN, H. Alternative Processing Technology for Converting Vegetable Oils and Animal Fats to Clean Fuels and Light Olefins. Chinese J. of Chem. Eng., v. 16, n. 3, p. 394-400, 2008.

TREACY, .M.J.; HIGGINS, J. B. Collection of Simulated XRD Powder Patterns for Zeolites. Amsterdam: Elsevier, 2001.

TWAIQ, F. A. .; MOHAMAD, A. .; BHATIA, S. Performance of composite catalysts in palm oil cracking for the production of liquid fuels and chemicals. Fuel Proc. Tech., v. 85, n. 11, p. 1283-1300, 2004.

TWAIQ, F. A.; ZABIDI, N. A. M.; BHATIA, S. Catalytic Conversion of Palm Oil to Hydrocarbons: Performance of Various Zeolite Catalysts. Industrial \& Engineering Chemistry Research, v. 38, n. 9, p. 3230-3237, 1999.

YANG, Y.; WANG, Q.; ZHANG, X.; WANG, L.; LI, G. Hydrotreating of C18 fatty acids to hydrocarbons on sulphided NiW/SiO2-Al2O3. Fuel Proc. Tech., v. 116, p. 165-174, 2013. Elsevier B.V. 